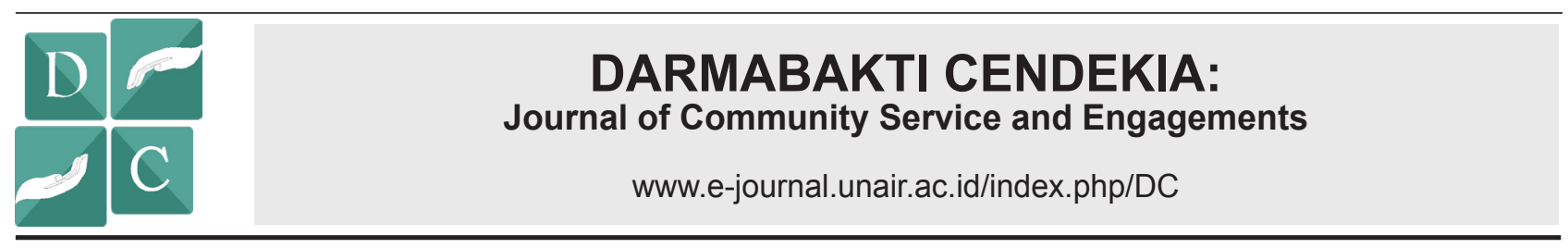

\section{ENHANCEMENT OF DIGITAL BASED BATIK CRAFT PRODUCTS IN KEREK DISTRICT, TUBAN DISTRICT}

\author{
PENINGKATAN PEMASARAN PRODUK KERAJINAN BATIK \\ BERBASIS DIGITAL DI KECAMATAN KEREK, KABUPATEN TUBAN
}

Scope:

Social economy

\author{
Ratna Azis Prasetyo ${ }^{1^{*}}$, Septi Ariadi ${ }^{1}$, Udji Asiyah ${ }^{1}$ \\ ${ }^{1}$ Study Program of Sociology, Faculty of Social Science and Political Science, Universitas Airlangga, Surabaya-Indonesia
}

\begin{abstract}
A B S T R A C T
Background: Gedog batik weaving in Kerek District to become one of the regional superior products that started local development. The MEA era and the industrial revolution 4.0 provide challenges for these creative economies to survive amid increasingly fierce global competition. One of them is by comparison with the shift of consumer tastes. UMKM are those who become Gedog batik weavers who do not understand customer satisfaction at present, which emphasizes the value of goods purchased according to the value used first. UMKM also specializes in mastering digital technology as a marketing medium. Purpose: For this reason, community adoption activities for training and mentoring for batik UMKM participants in making branding to respond to customer convenience and increasing marketing of digital-based products for solutions that support partnerships. Method: Community service methods are carried out by providing training and practicum on product branding and digital-based marketing for business entrepreneurs or batik artisans. Results: The result of these activity participants who initially did not understand the transition of consumers became aware of the need to do the branding of a digitalbased product and marketing. Conclusion: Partners get increased knowledge and skills in digital-based batik marketing to respond to shifting consumer tastes.
\end{abstract}

\section{A B S T R A K}

Latar belakang: Kerajinan batik tenun gedog di Kecamatan Kerek menjadi salah satu produk unggulan daerah yang menghidupkan perekonomian lokal. Era MEA dan revolusi industri 4.0 memberikan tantangan bagi para pelaku ekonomi kreatif ini untuk dapat tetap survive ditengah persaingan global yang semakin ketat. Salah satunya adalah dengan beradaptasi terhadap pergeseran selera konsumen. Yang menjadi permasalahan pelaku UMKM adalah mereka sebagai pelaku usaha batik tenun gedog belum menyadari adanya pergeseran selera konsumen saat ini yang lebih menekankan nilai kedua dari suatu barang daripada mengkonsumsi barang berdasarkan nilai kegunaan pertama suatu barang. Pelaku UMKM juga memiliki permasalahan dalam penguasaan teknologi digital sebagai media pemasaran. Tujuan: Memberikan pelatihan dan pendampingan kepada pelaku UMKM batik dalam membuat branding untuk merespon pergeseran selera konsumen dan melakukan peningkatan pemasaran produk berbasis digital sebagai solusi dari permasalahan yang tengah dihadapi mitra. Metode: pengabdian masyarakat yang dilakukan ini dengan memberikan pelatihan dan praktikum tentang branding produk dan pemasaran berbasis digital kepada pelaku usaha atau perajin batik. Hasil: Dari kegiatan ini peserta yang pada awalnya belum mengetahui pergeseran selera konsumen menjadi sadar pentingnya melakukan branding terhadap suatu produk dan pemasaran berbasis digital. Kesimpulan: Mitra mendapat peningkatan pengetahuan dan keterampilan dalam pemasaran batik berbasis digital untuk merespon pergeseran selera konsumen.

\author{
ART I CLE INFO \\ Recieved 20 Desember 2019 \\ Accepted 18 November 2020 \\ Online 6 Desember 2020 \\ *Correspondence (Korespondensi): \\ Ratna Azis Prasetyo \\ E-mail: \\ ratna.azis.prasetyo@fisip.unair. \\ ac.id
}

\section{Keywords:}

UMKM; Digital based

marketing; MEA; Industry 4.0; Branding
Kata kunci:

UMKM; Pemasaran berbasis digital; MEA; Industri 4.0; Branding 


\section{PENDAHULUAN}

Kegiatan pengabdian masyarakat yang diusulkan ini merupakan tindak lanjut dari hasil penelitian "Pola Perilaku Konsumsi Kelas Menengah Urban di Era Postmodern". Kecamatan Kerek Kabupaten Tuban saat ini telah berkembang sebagai kecamatan yang memiliki ciri khas sebagai penghasil batik tenun gedok. Ada banyak UMKM yang bergerak dalam kegiatan ekonomi kreatif ini dan tersebar di beberapa desa. Desa yang menjadi embrio adalah Margirejo, Gaji, Kedongrejo dan Karanglo karena di desa-desa tersebut awal pertama kali orang memintal dan menenun kain lalu berkembang menjadi kerajian batik.

Nama batik tenun gedog sendiri mulai populer pada tahun 1987. Kepopuleran nama tersebut tidak lepas dari keberadaan perajin batik tenun gedog yang semakin hari jumlahnya semakin bertambah. Pada tahun 2018 ini, terdapat sebanyak 1.234 unit sentra kerajinan batik tenun gedog dan mampu menyerap sebanyak 1.701 tenaga kerja (Pemerintah Provinsi Jawa Timur, 2018).

Pada awalnya batik tenun gedog tidak memiliki banyak motif, seiring dengan berjalannya waktu, banyak perajin batik tenun gedog yang menciptakan motif-motif baru. Beberapa jenis motif yang ada sekarang yaitu seperti ganggeng, kembang randu, kembang waluh, cuken, melati selangsang, satriyan, guntingan, kijing miring, panjiori, lingkasan kothong, panji krentil, kenongo uleren, panji serong dan panji konang.

Keunikan dari batik tenun gedog ini ada pada proses pembuatan yang panjang yaitu mulai dari memintal benang, menenun, mambatik dan melakukan pewarnaan dengan bahan alami. Dari proses memintal benang hingga menjatik batik dibutuhkan waktu kurang lebih selama tiga bulan.

Dari sisi manajemen usaha, batik tenun gedog telah dikerjakan secara turun temurun oleh warga di Kecamatan Kerek. Tenaga kerja banyak melibatkan sanak keluarga maupun tetangga sekitarnya yang memiliki kemampuan membatik. Para pembatik ini rata-rata tidak memiliki pendidikan yang tinggi karena mereka lebih mengandalkan skill dalam membatik.

Sedangkan pemasaran sebagian besar pelaku usaha masih melakukan dengan cara konvensional yaitu dari mulut ke mulut, di pasar-pasar, di lokasi pariwisata dan beberapa pelaku usaha besar mengikuti pameran baik di tingkat regional maupun nasional.

Memasuki era MEA, persaingan usaha menjadi semakin ketat karena banyaknya produk luar negeri yang masuk. Mau tidak mau, para pelaku usaha dituntut untuk lebih kreatif dan inovatif terutama dalam hal pemasaran agar dapat memperluas pasar dan menjangkau pasar global.
Tantangan berikutnya yang dihadapi dalam pemasaran ini semakin besar seiring dengan adanya pergeseran selera konsumen dan revolusi indutri 4.o. Banyak perajin skala kecil dan mikro belum dapat merespon pergeseran selera konsumen terhadap nilai kedua suatu barang (essart)(Suyanto, 2014). Artinya, di era postmodern saat ini orang tidak mengkonsumsi barang atas dasar kegunaan tetapi ada pertimbangan lainnya seseorang membeli suatu barang seperti brand, identitas dan gaya hidup (Chaney, 2011). Bahkan strategi pasar yang efektif, mampu mengaburkan antara kebutuhan dasar dan konsumsi berlebih (Mohan, 2011).

Adanya revolusi industri 4.0 juga telah menggeser cara konsumen dalam melakukan konsumsi dari yang konvensional menjadi serba digital. Teknologi digital diakui telah banyak memberikan manfaat positif dalam pemasaran suatu produk. Selain menawarkan kemudahan bertransaksi, keberadaan teknologi digital menjadikan pemasaran barang bisa lebih luas. Bagi para pelaku usaha batik tentunya akan lebih mudah memperkenalkan produk mereka kepada masyarakat melalui teknonolgi digital.

Oleh sebab itu, artikel ini bertujuan untuk memberikan solusi bagi para perajin batik di Kecamatan Kerek untuk meningkatkan pemasaran produk kerajinan batik berbasis digital. Tujuannya selain merespon pergeseran selera pasar juga memperluas jaringan pemasaran mereka dalam era global yang semuanya berbasis pada teknologi digital.

\section{METODE}

Metode yang dilakukan adalah dengan melakukan pelatihan dan praktikum kepada pelaku UMKM batik di Kecamatan Kerek Tuban. Para pelaku UMKM diberikan pelatihan yang pertama tentang membuat branding dari produk mereka kemudian dilakukan praktikum. Kedua, para pelaku UMKM batik diberikan pelatihan tentang pemasaran produk berbasis digital dan melakukan praktikum pembuatan toko online di media sosial maupun e-commerce. Pelatihan dilakukan dengan pemberian materi kepada para pelaku UMKM untuk memberikan wawasan serta meningkatkan kemampuan mereka dalam pemasaran produk. Setelah dilakukan pelatihan, peserta melakukan praktikum secara mandiri untuk membuat branding produk dan membuat toko online di media sosial.

\section{HASIL DAN PEMBAHASAN}

Kegiatan pengabdian masyarakat yang 
dilakukan di Kecamatan Kerek diikuti oleh 50 peserta yang merupakan pelaku UMKM batik. Para peserta pengabdian kepada masyarakat tersebut memiliki skala usaha yang berbeda-beda dengan segmen pasar yang berbeda. Sebagian merupakan pelaku UMKM batik yang telah memiliki skala besar dengan segmen pasar berskala nasional, namun sebagian besar merupakan pelaku UMKM skala kecil dengan segmen pasar regional bahkan masih tergantung kepada pelaku UMKM skala besar dalam memasarkan produknya.

Ada banyak hambatan yang dialami oleh para pelaku UMKM batik skala kecil di Kecamatan Kerek meliputi minimnya kepemilikan modal dan aset produksi, mahalnya harga bahan baku serta akses pasar yang terbatas, sementara pasar lokal saat ini sudah sangat bersaing dengan produkproduk dari daerah lain.

Saat ini, sebagian besar dari mereka masih banyak yang tergantung kepada pelaku UMKM lain karena keterbatasan pengetahuan mereka dalam merespon pergeseran selera konsumen di era digital serta masih rendahnya penguasaan teknologi digital sebagai sarana pemasaran. Merespon permasalahan yang dihadapi oleh para perajin batik di Kerek Tuban, dalam kegiatan pengabdian masyarakat ini telah dilaksanakan beberapa kegiatan.

Pertama, kegiatan yang dilakukan adalah pelatihan bagaimana cara membranding produk batik mereka yang sesuai dengan selera pasar saat ini. Tidak bisa dipungkiri bahwa pada era postmodern ini selera pasar banyak mengalami pergeseran dimana konsumen dalam mengkonsumsi sebuah produk tidak lagi bertumpu pada kegunaan utama produk tersebut melainkan pada nilai kedua suatu (essart) yang kesemuanya terkait dengan lifestyle. Untuk menumbuhkan pengatahuan tentang nilai kedua suatu barang dilakukan sosialisasi tentang nilai kedua sebagaimana terlihat dalam gambar 1

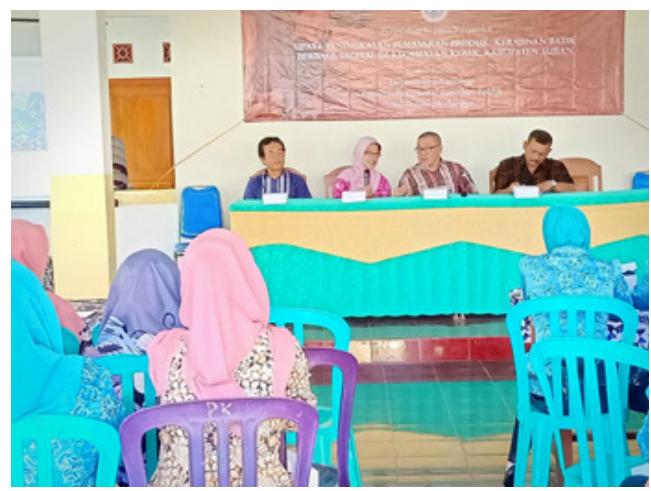

Gambar 1. Sosialisasi tentang perubahan selera konsumen pada nilai kedua barang

Branding dilakukan untuk membentuk image produk batik masing-masing perajin agar produk yang mereka tawarkan ke konsumen memiliki ciri khas tersendiri dibanding dengan produk yang lain. Dalam kegiatan ini, peserta diajak untuk menggali motif-motif batik Kerek Tuban serta nilai-nilai history dibalik motif tersebut yang bisa dituliskan dalam kemasan produk batik mereka. Branding tersebut bisa mencantumkan nilai history, maupun cara pembuatan produk.

Teknik yang diajarkan ke peserta dalam membuat branding tersebut dengan sederhana yaitu dengan meminta peserta untuk membuat gambaran tentang peserta lain yang ada di sebelah mereka. Teknik kami buat dengan cara yang sederhana agar peserta lebih mudah untuk memahami bagaimana cara membuat branding pada produk mereka sebagaimana terlihat pada gambar 2.

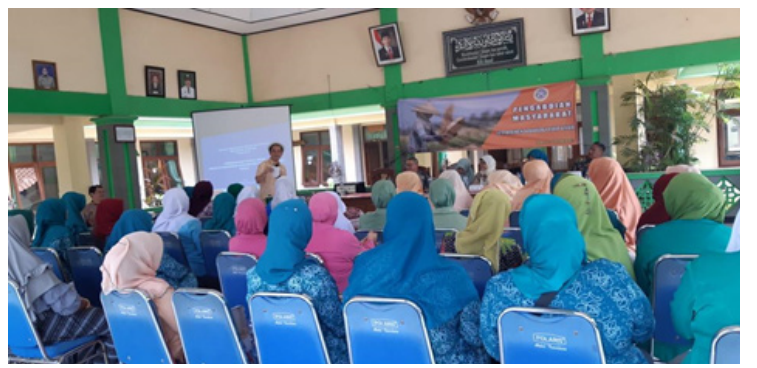

Gambar 2. Pelatihan branding produk pada perajin batik

Kedua, adalah kegiatan pemasaran produk berbasis digital. Perkembangan teknologi digital telah memberikan dampak pada terjadinya pergeseran selera konsumen. Konsumen di era digital sekarang ini, masyarakat lebih banyak menghabiskan waktunya untuk berselancar di dunia maya untuk mencari referensi apapun tidak terkecuali semua hal yang terkait dengan kebutuhan konsumsi mereka.

Perkembangan teknologi digital telah membawa perubahan besar pada bidang industry terutama revolusi industry 4.0 yang semuanya berbasis digital. Diawali dengan lahirnya social media seperti facebook, twitter, Instagram, e-commers lalu kemudian start up banyak membawa perubahan pada pola-pola pemasaran suatu produk. Banyak produsen dituntut untuk berinovasi dan semakin kreatif dalam mengembangkan usahanya di era industri 4.0. Bagi yang tidak bisa mengikuti perkembangan tersebut, maka akan kalah bersaing dengan produsen lain yang mampu merespon perubahan. Suka atau tidak suka, perilaku konsumen telah berubah seiring dengan perubahan akibat teknologi digital.

Demikian yang dialami oleh para perajin batik gedog di Kerek Tuban terutama mereka yang merupakan perajin dengan skala usaha kecil. Salah satu yang mereka rasakan pada perkembangan 
usaha mereka adalah jumlah produksi yang semakin berkurang akibat banyaknya persaingan. Saat ini, masih banyak perajin yang memasarkan produk mereka dengan cara-cara konvensional dan tidak berbasis digital.

Salah satu solusi yang kami tawarkan kepada mereka adalah pemasaran berbasis digital. Awalnya kami memberikan pengatahuan kepada mereka tentang pemasaran berbasis digital dengan menggunakan e-commerce seperti tokopedia, shopee, atau bukalapak. Akan tetapi, mengingat sumber daya manusia dan modal yang terbatas, kami berpikir untuk melakukan hal yang sangat simple agar mudah dimengerti dan dilakukan oleh para peserta.

Kami melihat bahwa semua peserta telah memiliki smartphone serta telah menggunakan facebook sebagai social media sebagai bagian dari aktivitas mereka sehari-hari. Yang perlu dilakukan adalah bagaimana merubah mindset mereka dari menggunakan facebook sebagai bagian aktivitas sehari-hari menjadi bagian dari aktivitas bisnis mereka. Hal ini dilakukan karena mereka sudah bisa menggunakan facebook, sehingga akan lebih mudah jika dilatih untuk memasarkan produk melalui facebook sebagaimana dapat dilihat pada gambar 3 .

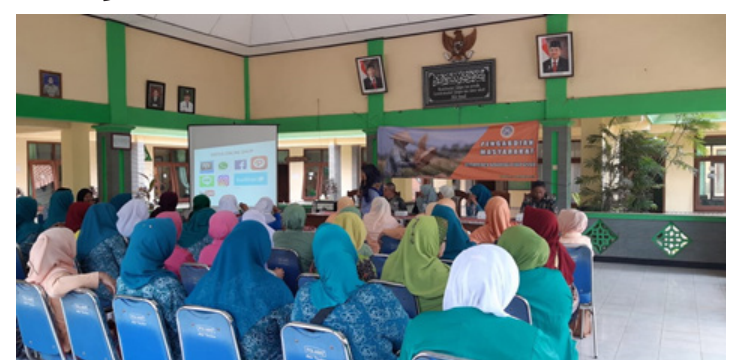

Gambar 3. Pelatihan penggunaan media sosial untuk pemasaran produk

Mereka bisa langsung memasarkan produk melalui facebook, dengan mencantumkan nama serta branding produk yang telah mereka buat. Selain facebook, media yang cukup mudah dilakukan untuk pemasaran produk adalah Instagram. Kami mengajarkan mereka untuk memasarkan produknya melalui Instagram serta strategi agar produk mereka mudah ditemukan dalam mesin pencarian Instagram.

Facebook dan Instagram kami pilih sebagai media pemasaran para perajin batik ini karena pertama, mempelajari penggunaan facebook dan instagram relative lebih mudah dilakukan dibanding dengan e-commerce maupun start up. Kedua, facebook dan Instagram digunakan oleh hampir semua orang tidak terbatas geografis. Artinya jangkauan pasarnya sangat luas dan telah menjadi bagian dari aktivitas setiap hari semua orang.

\section{KESIMPULAN DAN SARAN}

Pelaksanaan kegiatan pengabdian masyarakat bertujuan untuk meningkatkan keberdayaan pengrajin batik dalam menghadapi era digital dan pergeseran selera konsumen. Hasil dari kegiatan tersebut, ternyata masih banyak para perajin batik yang selama ini tidak menyadari adanya pergeseran selera konsumen sebagai akibat berkembangnya teknologi. Dari hasil kegiatan yang dilakukan, ada peningkatan pengetahuan di kalangan pelaku UMKM batik gedog tentang pentingnya merespon pergeseran selera konsumen di era digital. Para pelaku UMKM batik bisa melakukan branding produk serta menggunakan media sosial (facebook, instagram, start up) sebagai metode pemasaran di era digital.

\section{UCAPAN TERIMA KASIH}

Kami mengucapkan banyak terimakasih kepada Pemerintah Kecamatan Kerek Kabupaten Tuban yang telah melaksanakan dan memfasilitasi kegitan pengabdian kepada masyarakat. Penulis menyatakan tidak ada konflik kepentingan dengan pihak-pihak yang terkait dalam kegiatan pengabdian kepada masyarakat ini.

\section{DAFTAR PUSTAKA}

Chaney, D. 2011. Lifestyles: Sebuah Pengantar Komprehensif. Yogjakarta \& Bandung: Jalasutra.

Mohan, K. 2011. Cultural Values and Globalization: India's Dilemma. Current Sociology Vol. 59(2). Pp. 214-228.

Pemerintah Provinsi Jawa Timur. 2018. Sentra Kerajinan Batik Tenun Gedog Tuban Capai 1.234 Unit. Available from: http://jatimprov. go.id/read/berita-pengumuman/sentrakerajinan-batik-tenun-gedog-tuban-capai-1234-unit. Accessed: 21 Oktober 2018.

Suyanto, B. 2014. Sosiologi Ekonomi: Kapitalisme dan Konsumsi di Era Masyarakat PostModernisme. Jakarta: Prenada Media. 